\title{
Graphite-epoxy Composite Design for Aircrcaft Wing Spar Using Computational Techniques - Part I
}

\author{
AKINDAPO Jacob Olaitan*, JOHNSON-ANAMEMENA Nnaemeka, GARBA Danladi King \\ Department of Mechanical Engineering, Nigerian Defence Academy, Kaduna - Nigeria \\ *Corresponding author: jacobakindapo@gmail.com
}

\begin{abstract}
This research work investigates graphite-epoxy design for light weight high performance structure of an aircraft wing spar using computational techniques. MATLAB MuPAD software was used to derive analytical models for the aircraft wing loads using symbolic computation to estimate shear and bending moment forces acting on the wings while ANSYS 14 Mechanical APDL software was used to design and analyze the modeled composite structures of the wing spar. To carry out progressive failure analyses of the various graphite-epoxy composite wing spar designs under bending moment, finite element analysis with ANSYS 14 Mechanical APDL software was employed to determine which spar design would best withstand the bending moment of 10,000Nm generated from the MATLAB MuPAD software. The investigation revealed that all the three designs of Low Modulus (LM) spar, High Modulus (HM) spar and Ultra Modulus (UM) spar failed at 16,801.8 N/ $\mathrm{m}^{2}$ which is above the wing bending moment with ultra-modulus spar having the least deflection of $0.143 \times 10^{-3} \mathrm{~m}$ because of its high stiffness property.
\end{abstract}

Keywords: aircraft wing spar, computational technique, Finite Element Analysis (FEA), graphite-epoxy design, shear force and bending moment

Cite This Article: AKINDAPO Jacob Olaitan, JOHNSON-ANAMEMENA Nnaemeka, and GARBA Danladi King, "Graphite-epoxy Composite Design for Aircrcaft Wing Spar Using Computational Techniques Part I.” American Journal of Mechanical Engineering, vol. 5, no. 4 (2017): 117-127. doi: 10.12691/ajme-5-4-2.

\section{Introduction}

The development of composite materials, related design and manufacturing technologies are one of the most important advances in the history of materials. Big performance gains are already well in hand for the class of materials called composites in which one type of material is reinforced by particles, fibers or plates of another type. Among the first engineered composites was fiberglass, developed in the 1930s, made by embedding glass fiber in a polymer matrix, it found use in building panels, bathtubs, boat hulls, and other marine products [10] . Developments in the lab or factory interacted with major world events in the 1960s prompted the use of new and stronger reinforcement fibers; graphite (carbon) fibers were produced using rayon as the starting compound, and Texaco announced the high stiffness and strength of boron fibers they had developed. While carbon and boron fibers were developed around the same time, carbon took the lead in the 1960s due to its superior processing capabilities and its lower cost.

In Japan, Shindo developed high strength graphite fibers using polyacryonitrile as the precursor in 1961, replacing the rayon and pitch precursors used previously [14]. In 1971 DuPont introduced the world to Kevlar, a fiber based on an aramid compound developed by Stephanie Kwolek back in 1964. Aramids belong to the nylon family of polymers, their key structural features are aromatic rings (basically benzene rings) linked by amide groups. Kwolek had been working on petroleum-based condensation polymers in an effort to develop stronger and stiffer fibers. The looming possibility of an energy shortage had convinced DuPont that light polymer-based fibers for radial tires could replace the steel belts then in use, reducing the overall weight of the car and saving fuel [12]. Whereas, space and aircraft demands had prompted the quest for new high modulus fibers in the 1960s, composites made with such expensive fibers had to find civil applications in the 1970s, when space and military demands declined. Sports and automobile industries became the more important markets.

Myer described composites as multifunctional materials having unprecedented mechanical and physical properties that can be tailored to meet the requirements of a particular application [9]. Many composites exhibit great resistances to high-temperature corrosion, oxidation and wear. These unique characteristics provide the mechanical engineer with design opportunities not possible with conventional monolithic materials. In addition, various processes of manufacturing composite are well suited to the fabrication of large, complex structures, which allows consolidation of parts and thereby reducing manufacturing cost [9].

Ithurbure in 1999 stated that in the case of aircraft, composites mainly are fiber reinforced plastics. This means that the composites consist of fibers and a material, which keeps these fibers together, called matrix [5].

Composites are classified into four categories depending on the kind of material used for the matrix. The four primary categories are Polymer Matrix Composites 
(PMCs), Metal Matrix Composites (MMCs), Ceramics Matrix Composites (CMCs), and Carbon/Carbon Composites (CCCs). At this time, PCMs are the most widely used class of composites. However, there are important applications of the other types, which are indicative of their great potential in mechanical engineering applications [2].

One simple scheme for the classification of composite materials based on reinforcement properties consist of three main divisions: particle-reinforced, fiber-reinforced and structural composites.

One distinguished property of composite materials is that they are strongly heterogeneous materials; this implies, its properties vary considerably from point to point in the material, unlike its monolithic ceramics and metallic alloys counterparts which are usually considered homogeneous, to a first approximation.

Many artificial composites, especially those reinforced with fibers, are anisotropic, which implies their properties vary with direction in addition to being heterogeneous in nature [2].

A lot of fiber-reinforced composites, in most cases PMCs, CCCs, and MMCs, do not demonstrate plastic behaviour as metals would do, which makes them more susceptible to stress concentrations. This does not mean they are brittle materials like monolithic ceramics, rather their heterogeneous nature results in complex mechanisms that impart toughness. The unique characteristics of composite materials, especially anisotropy, require the use of special design methods [9].

\section{Review of Existing Literatures}

Mohamed and Nithiyakalyani in 2014 worked on the design and structural analysis of ribs and spars of swept back wing regional aircraft capable of carrying 150 passengers. The optimum design parameters were suitably selected and then the model was designed using the CATIA software in order to determine stresses and displacements due to the applied loads. Then it was observed that, although the yield stress of aluminium ranges between $200 \mathrm{~N} / \mathrm{mm}^{2}$ to $600 \mathrm{~N} / \mathrm{mm}^{2}$ the final result showed that the required stress value of the wing was 487 $\mathrm{N} / \mathrm{mm}^{2}$. Introducing a third spars with the designed thickness increased the strength, thereby making the wing safe and not easily buckled [8].

Victor and Bikramjit in 2014 investigated the maximum deflection and von-Misses stress of simply supported beam and cantilever beam under two different types of loading i.e. point load and uniformly distributed load applied on a rectangular section beam subjected to bending moment and shear force. The material of the member was observed to offer resistance or stresses against these deformations. They stated that it is possible to estimate these stresses with certain assumptions. Firstly, theoretical calculations were done based on the general EulerBernoulli's Beam Equation. After which Computational Analyses on ANSYS 14.0 software were performed. Comparing the Numerical Results with that of the ANSYS 14.0 showed that excellent accuracy of the present method (i.e. ANSYS 14.0) was visualized using Beam 189 element as compared to Beam 188 element and other Solid elements [13].

The present work is on the design of aircraft wing spar with graphite epoxy using computational techniques.

\section{Analytical Modeling of Wing Load}

There are three primary loads that acts on the aircraft wing: aerodynamic lift, load due to structure weight and load due to the fuel contained in the wing. These loads act perpendicularly to the wing surface and their magnitude varies along the length of the wing [3].

\subsection{Lift}

The lift model was based on an elliptical distribution of lift across the length of the wing; therefore, the lift profile can be expressed as;

$$
q_{l}(x)=k a \sqrt{L^{2}-x^{2}} .
$$

By integration across the length of the wing, the total lift produced can be expressed as;

$$
q_{l}(x)=\frac{2 W t_{o} n \sqrt{L^{2}-x^{2}}}{\pi L^{2}} .
$$

It can be seen from this analytical expression that lift is directly proportional to load factor (n). Therefore, for a load factor of 1 during straight flight, the maximum lift is;

$$
q_{l \max }(x)=\frac{2 W t_{o}}{\pi L} .
$$

This occurs at the wing root $(x=0)$.
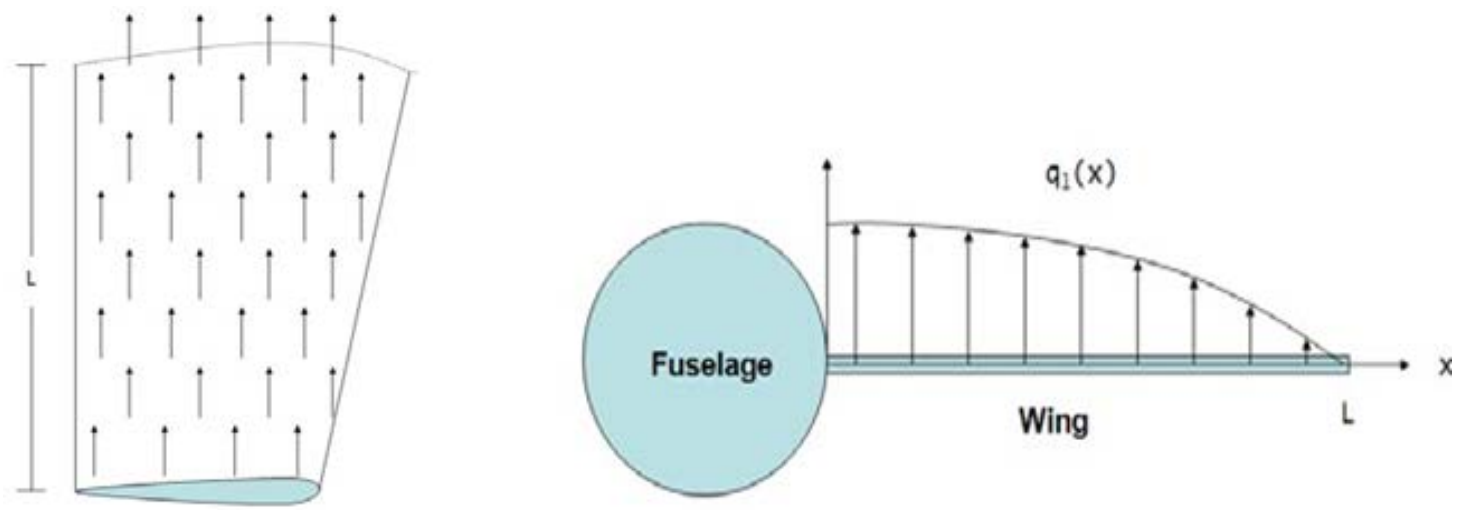

Figure 1. Lift on the wing 

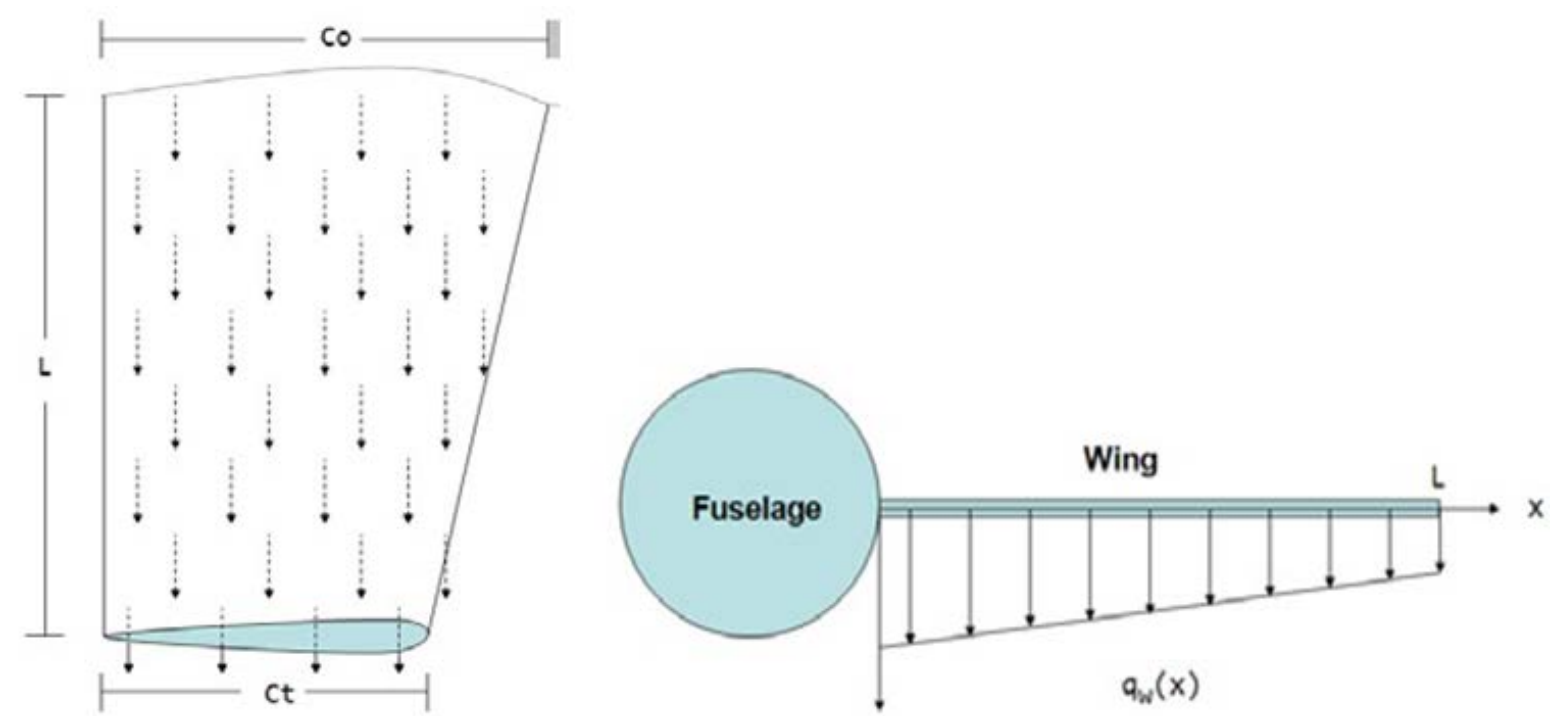

Figure 2. Load due to wing structure weight
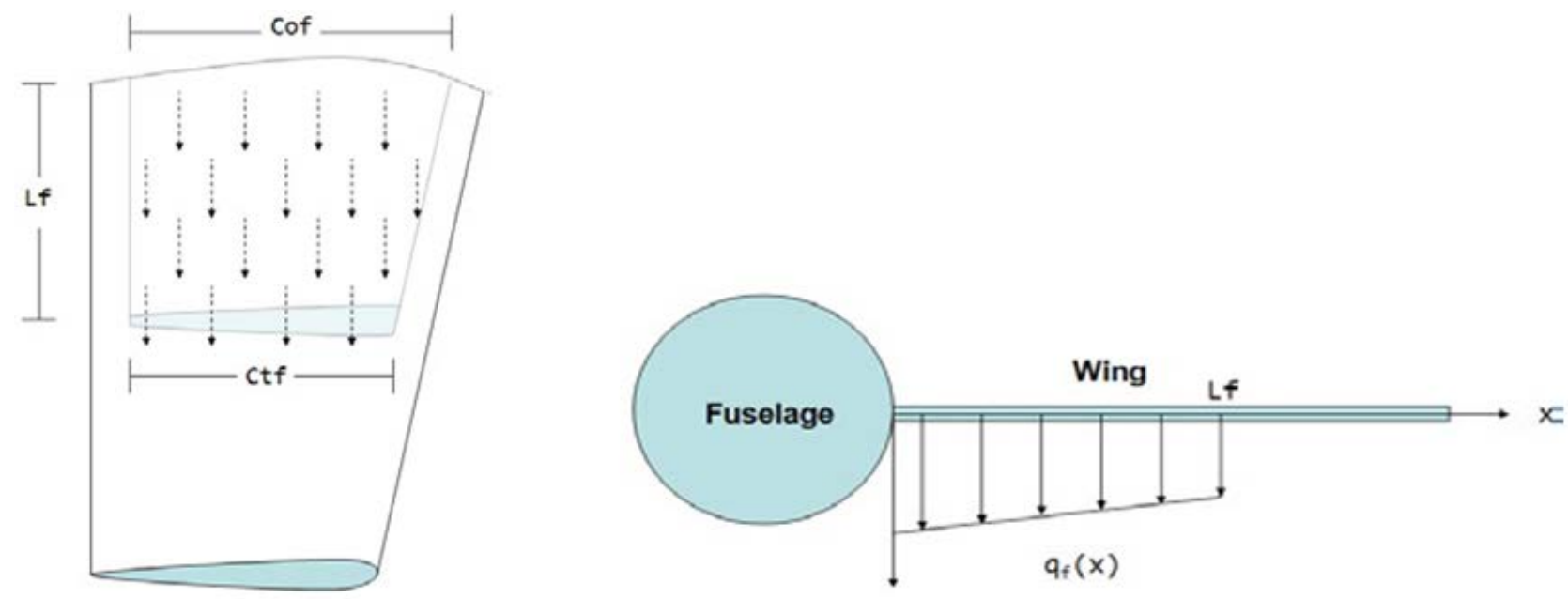

Figure 3. Load due to the weight of the fuel stored in the wing

\subsection{Weight of Wing Structure}

It was assumed that the load caused by the weight of the wing structure is proportional to the chord length (the width of the wing), which is highest at the wing base $\left(C_{0}\right)$ and tapers off towards the wing tip $\left(C_{t}\right)$. Hence, the load profile can be expressed as:

$$
q_{w}(x)=K w\left(\frac{C_{t}-C_{o}}{L} x+C_{o}\right) .
$$

By integrating across the length of the wing, the total load from the wing structure can be expressed as;

$$
=\frac{K w L\left(C_{o}+C_{t}\right)}{2} \text {. }
$$

Equation (5) being the structural load equation can be equated with the structural load expressed in terms of load factor and weight of the wing structure to obtain;

$$
q_{w}(x)=-\frac{W w s n\left(C_{o}-\frac{x\left(C_{o}-C_{t}\right)}{L}\right)}{L\left(C_{o}+C_{t}\right)} .
$$

\subsection{Weight of Fuel Stored in Wing}

The load due to the weight of the fuel stored in the wing can be defined as a piecewise function where load is zero when $\mathrm{x}>$ Lf. It was assumed that this load is proportional to the width of the fuel tank, which is at its maximum at the base of the wing and tapers off towards the tip of the fuel storage tank.

It can be shown without any loss of generality that;

$$
q_{f}(x)= \begin{cases}0 & \text { if } L f<x \\ -\frac{W f n\left(C_{o} f-\frac{x\left(C_{o} f-C_{t} f\right)}{L f}\right)}{L f\left(C_{o} f+C_{t} f\right)} & \text { if } x \leq L f\end{cases}
$$

\subsection{Total Load}

The total load can be obtained by adding the three individual load components. This analytical model gives a clear view of how aircraft weight and geometry parameters affect total load, i.e.;

$$
q_{t}(x)=q_{l}(x)+q_{w}(x)+q_{f}(x) .
$$




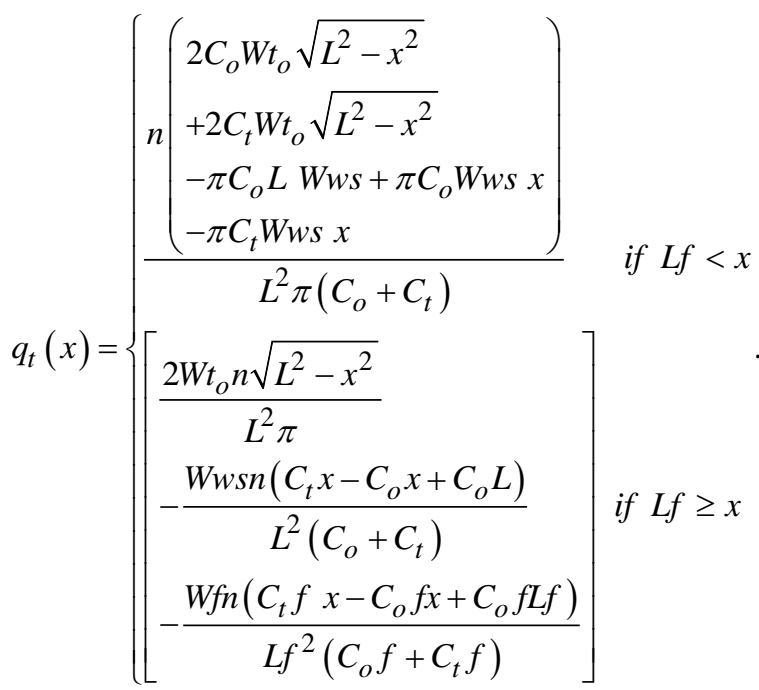

\subsection{Shear Force and Bending Moment Models}

One can use the expression that was derived for load on the wing to calculate the bending moment. The shear force can be determined from;

$$
V(x)=-\int q_{t}(x) d x .
$$

Therefore, bending moment can be calculated by integrating shear force to yield;

$$
M(x)=\int V(x) d x .
$$

\subsection{Load Factor}

The load factor is equal to the ratio of 'Lift' to 'Total aircraft weight'. Using the standard lift equation, and assuming the aircraft is not banking, load factor can be expressed as:

$$
n=\frac{\rho A C_{L} V^{2}}{2 W t_{o}} .
$$

It is worthy of note to state that the various mathematical/analytical models starting from equation 1 through 12 can be plugged into MATLAB MuPAD Appliation to carry out desired mechanical simulations for wing analyses.

\subsection{Designing Wing Spar to Withstand Bending Moment.}

\section{Airfoil Selection}

NACA 2415 was selected for the design of the small passenger aircraft wing. The airfoil section is responsible for the generation of the optimum pressure distribution on the top and bottom surfaces of the wing such that the required lift is created with the lowest aerodynamic cost.

\subsection{Four-digit Series}

According to National Advisory Committee for Aeronautics (NACA) [6], the four-digit series specifies the following:

$1^{\text {st }}$ digit: specifies the maximum camber $(m)$ in percentage of the chord (airfoil length).

$2^{\text {nd }}$ digit: indicates the position of the maximum camber $(p)$ in tenths of chord.

$3^{\text {rd }}$ and $4^{\text {th }}$ digits: provide the maximum thickness $(t)$ of the airfoil in percentage of chord.

Utilizing ' $m$ ', ' $p$ ' and ' $t$ ' values, one can compute the coordinates for an entire airfoil using the following relationships:

$$
\begin{gathered}
y_{C}=\frac{m}{p^{2}}\left(2 p x-x^{2}\right) \text { from } x=0 \text { to } x=p \\
y_{C}=\frac{m}{(1-p)^{2}}\left[(1-2 p)+2 p x-x^{2}\right] \text { from } x=p \text { to } x=c .(14)
\end{gathered}
$$

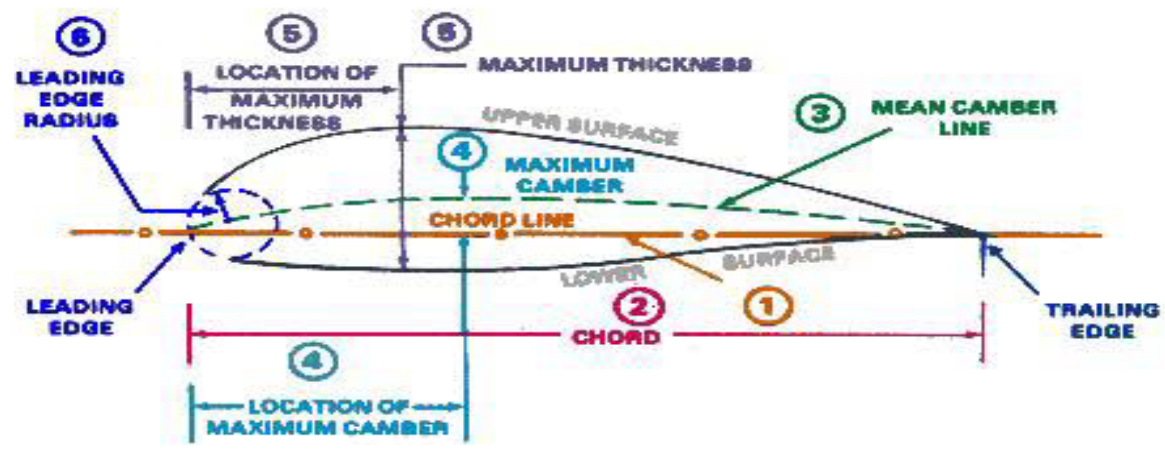

Figure 4. Airfoil Terminology (Source: Dynamic Flight Inc. [4])

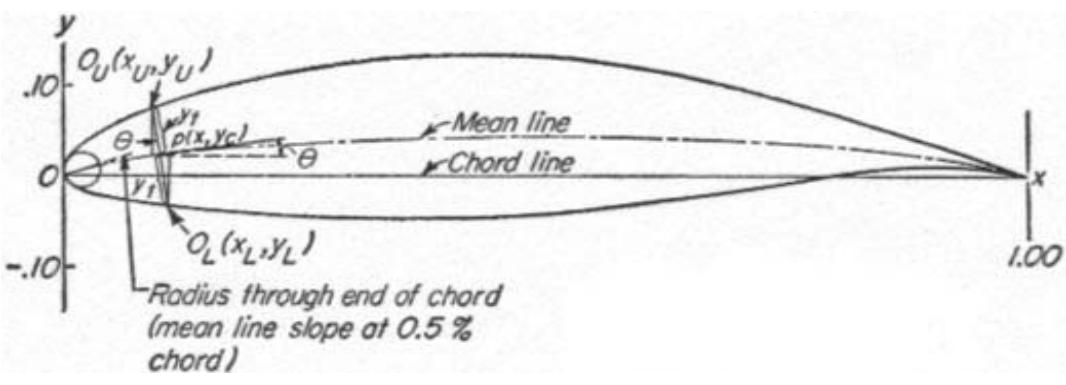

Figure 5. Primary Variables of Airfoil (Source: Jeff Scott [6]) 
The thickness distribution above $(+)$ and below (-) the mean line was evaluated by plugging in the value of $t$ into the equation for $x$ coordinates.

$$
\pm y_{t}=\frac{t}{0.2}\left(\begin{array}{l}
0.2969 \sqrt{x}-0.1260 x-0.3516 x^{2} \\
+0.2843 x^{3}-0.1015 x^{4}
\end{array}\right) .
$$

The final coordinates for the upper surface $\left(x_{u}, y_{u}\right)$ and lower surface $\left(x_{l}, y_{l}\right)$ were determined using the construction in Figure 5.

\subsection{Spar Design for Wing}

A cambered or asymmetric airfoil of NACA 2415 was selected for its aerodynamic lift capability compared to its symmetric counterpart NACA 0015.

For the purpose of this work, the maximum thickness of the airfoil which will determine the total depth of the spar that will run along the entire length of the wing was only considered.

\subsection{Employing the I-section Beam for Spar Design}

To make the stiffest beam with least amount of material, the I-section was selected as the choice design shape of the spar for this work. This is because more materials will only need to be at the top and bottom sides forming the flanges with a thin connecting web between them. The flanges resist the bending moment stress while the web resists most of the shear stress.

Increasing the depth of the beam increases the bending strength so we can gain stiffness this way, but not without buckling and deflection which occur when the web starts getting thin.

Since stress and strain are directly proportional to each other, to have a lower strain or deflection, we need a high section modulus for the beam. The section modulus of an I-section when compared to a solid rectangular section is much higher. The reason is that in the I-section more fibers are distributed away from the neutral axis, but hollow beams are more efficient than solid beams of the same cross sectional area $[7,11]$.

\subsection{ANSYS Equation for Preintegrated Composite Spar Using Beam188 or Beam189}

For composite spars made of dissimilar constituent materials, or homogeneous spars with orthotropic material and material orientation not parallel to the spar axis, the coupling between different generalized strains can be significant and generally leads to full cross-section stiffness matrix [1].

The full cross-section stiffness relates the generalizedstress to generalized-strain in the following form:

$$
\left[\begin{array}{c}
N \\
M_{1} \\
M_{2} \\
\tau \\
S_{1} \\
S_{2} \\
B_{m}
\end{array}\right]=\left[\begin{array}{r}
S_{11}(T) S_{12}(T) S_{13}(T) S_{14}(T) S_{15}(T) S_{16}(T) S_{17}(T) \\
S_{22}(T) S_{23}(T) S_{24}(T) S_{25}(T) S_{26}(T) S_{27}(T) \\
S_{33}(T) S_{34}(T) S_{35}(T) S_{36}(T) S_{37}(T) \\
S_{44}(T) S_{45}(T) S_{46}(T) S_{47}(T) \\
S_{55}(T) S_{56}(T) S_{57}(T) \\
S_{66}(T) S_{67}(T) \\
S_{77}(T)
\end{array}\right]
$$

If a unit spar length is considered, the section mass matrix relates the resultant forces and torques to acceleration and angular accelerations as follows (applicable to the local element coordinate system):

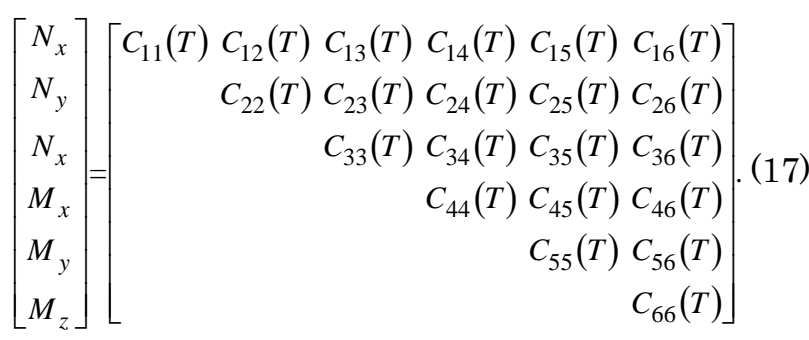

\section{Materials, Equipment and Methods}

\subsection{Materials}

The major materials used for this research work are:

i. Low Modulus Graphite-Epoxy Lamina.

ii. High Modulus Graphite-Epoxy Lamina.

iii. Ultra Modulus Graphite-Epoxy Lamina.

The design properties employed are reflected in Table 1 to Table 4 below:

(a) Low Modulus (LM) Graphite-Epoxy Lamina.

Table 1. Design Values for Low Modulus (LM) Graphite-Epoxy Composite

\begin{tabular}{|l|l|}
\hline Material Properties & Value \\
\hline Thickness $(\mathrm{m})$ & 0.00023 \\
\hline $\mathrm{E}_{11}\left(\mathrm{~N} / \mathrm{m}^{2}\right)$ & $1.44790 \mathrm{E}+11$ \\
\hline $\mathrm{E}_{22}\left(\mathrm{~N} / \mathrm{m}^{2}\right)$ & $9.65266 \mathrm{E}+09$ \\
\hline $\mathrm{E}_{33}\left(\mathrm{~N} / \mathrm{m}^{2}\right)$ & $9.65266 \mathrm{E}+09$ \\
\hline $\mathrm{NU}_{12(\mathrm{xy})}$ & $2.5 \mathrm{E}-01$ \\
\hline $\mathrm{NU}_{23(\mathrm{yz})}$ & $4.065 \mathrm{E}-01$ \\
\hline $\mathrm{NU}_{13(\mathrm{xz})}$ & $2.5 \mathrm{E}-01$ \\
\hline $\mathrm{G}_{12(\mathrm{xy})}$ & $5.86054 \mathrm{E}+09$ \\
\hline $\mathrm{G}_{23(\mathrm{yz})}$ & $3.46117 \mathrm{E}+09$ \\
\hline $\mathrm{G}_{13(\mathrm{xz})}$ & $5.86054 \mathrm{E}+09$ \\
\hline Density $\left(\mathrm{Kg} / \mathrm{m}^{3}\right)$ & 1577.75 \\
\hline
\end{tabular}

Source: Lamina Data of Autodesk Simulation Composite Design 2015 Software.

(b) High Modulus (HM) Graphite-Epoxy Lamina.

Table 2. Design Values for High Modulus (HM) Graphite-Epoxy Composite

\begin{tabular}{|l|l|}
\hline Material Properties & Value \\
\hline Thickness $(\mathrm{m})$ & 0.00023 \\
\hline $\mathrm{E}_{11}\left(\mathrm{~N} / \mathrm{m}^{2}\right)$ & $2.20632 \mathrm{E}+11$ \\
\hline $\mathrm{E}_{22}\left(\mathrm{~N} / \mathrm{m}^{2}\right)$ & $6.89476 \mathrm{E}+09$ \\
\hline $\mathrm{E}_{33}\left(\mathrm{~N} / \mathrm{m}^{2}\right)$ & $6.89476 \mathrm{E}+09$ \\
\hline $\mathrm{NU}_{12(\mathrm{xy})}$ & $2.5 \mathrm{E}-01$ \\
\hline $\mathrm{NU}_{23(\mathrm{yz})}$ & $4.103 \mathrm{E}-01$ \\
\hline $\mathrm{NU}_{13(\mathrm{xz})}$ & $2.5 \mathrm{E}-01$ \\
\hline $\mathrm{G}_{12(\mathrm{xy})}$ & $4.82633 \mathrm{E}+09$ \\
\hline $\mathrm{G}_{23(\mathrm{yz})}$ & $2.71653 \mathrm{E}+09$ \\
\hline $\mathrm{G}_{13(\mathrm{xz})}$ & $4.82633 \mathrm{E}+09$ \\
\hline Density $\left(\mathrm{Kg} / \mathrm{m}^{3}\right)$ & 1633.11 \\
\hline
\end{tabular}

Source: Lamina Data of Autodesk Simulation Composite Design 2015 Software. 
(c) Ultra Modulus (UM) Graphite-Epoxy Lamina.

Table 3. Design Values for Ultra Modulus (UM) Graphite-Epoxy Composite

\begin{tabular}{|l|l|}
\hline Properties & Value \\
\hline Thickness $(\mathrm{m})$ & 0.00023 \\
\hline $\mathrm{E}_{11}\left(\mathrm{~N} / \mathrm{m}^{2}\right)$ & $2.89580 \mathrm{E}+11$ \\
\hline $\mathrm{E}_{22}\left(\mathrm{~N} / \mathrm{m}^{2}\right)$ & $6.20528 \mathrm{E}+09$ \\
\hline $\mathrm{E}_{33}\left(\mathrm{~N} / \mathrm{m}^{2}\right)$ & $6.20528 \mathrm{E}+09$ \\
\hline $\mathrm{NU}_{12(\mathrm{xy})}$ & $2.5 \mathrm{E}-01$ \\
\hline $\mathrm{NU}_{23(\mathrm{yz})}$ & $4.197 \mathrm{E}-01$ \\
\hline $\mathrm{NU}_{13(\mathrm{xz})}$ & $2.5 \mathrm{E}-01$ \\
\hline $\mathrm{G}_{12(\mathrm{xy})}$ & $4.82633 \mathrm{E}+09$ \\
\hline $\mathrm{G}_{23(\mathrm{yz})}$ & $2.65586 \mathrm{E}+09$ \\
\hline $\mathrm{G}_{13(\mathrm{xz})}$ & $4.82633 \mathrm{E}+09$ \\
\hline Density $\left(\mathrm{Kg} / \mathrm{m}^{3}\right)$ & 1688.47 \\
\hline
\end{tabular}

Source: Lamina Data of Autodesk Simulation Composite Design 2015 Software.

(d) Wing Design Properties: Aerofoil Model NACA 2415 for the wing of a small passenger aircraft.

Table 4. Aircraft and Visualize Wing Loads Parameters

\begin{tabular}{|c|l|c|}
\hline S/N & Wing Design Parameters & Value \\
\hline 1 & Total aircraft weight (Wto) & $4,800 \mathrm{~kg}$ \\
\hline 2 & Weight of wing structure (Wws) & $630 \mathrm{~kg}$ \\
\hline 3 & Weight of fuel stored in wing (Wf) & $675 \mathrm{~kg}$ \\
\hline 4 & Length of wing (L) & $7 \mathrm{~m}$ \\
\hline 5 & Length of fuel tank within wing (Lf) & $2.4 \mathrm{~m}$ \\
\hline 6 & Chord length of wing root (Co) & $1.8 \mathrm{~m}$ \\
\hline 7 & Chord length of wing tip (Ct) & $1.4 \mathrm{~m}$ \\
\hline 8 & Width of fuel tank at wing root (Cof) & $1.1 \mathrm{~m}$ \\
\hline 9 & Width of fuel tank at Lf (Ctf) & $0.85 \mathrm{~m}$ \\
\hline 10 & Load factor (n) & 1.5 \\
\hline
\end{tabular}

\subsection{Equipment}

The equipment used in this work is an Hp Compaq 615 personal computer. The following software applications were employed to carry out the various analyses:

i. MATLAB R2016a (9.0.0.341360) Software, by MathWorks, Inc.

ii. ANSYS 14 Mechanical APDL Software, by ANSYS Inc. USA.

\subsection{Methods}

The aircraft loads were modeled using MATLAB and symbolic Math Toolbox called MuPAD to determine the shear loads and bending moments on the wing of a small passenger aircraft. This was carried out with the aim of ascertaining whether the proposed designs meet strength requirements.

Thereafter, the developed stresses and displacements under static loading conditions were analyzed for spar composite designs using finite element methods with the help of ANSYS 14 Mechanical APDL.

\section{Results, Analysis and Discussions}

\subsection{MATLAB Results for Wing Loads Analytical Analysis.}

\subsubsection{Results for Total Load}

The results obtained for the load along the cross-section of the wing using MATLAB is shown in Figure 6 blow:

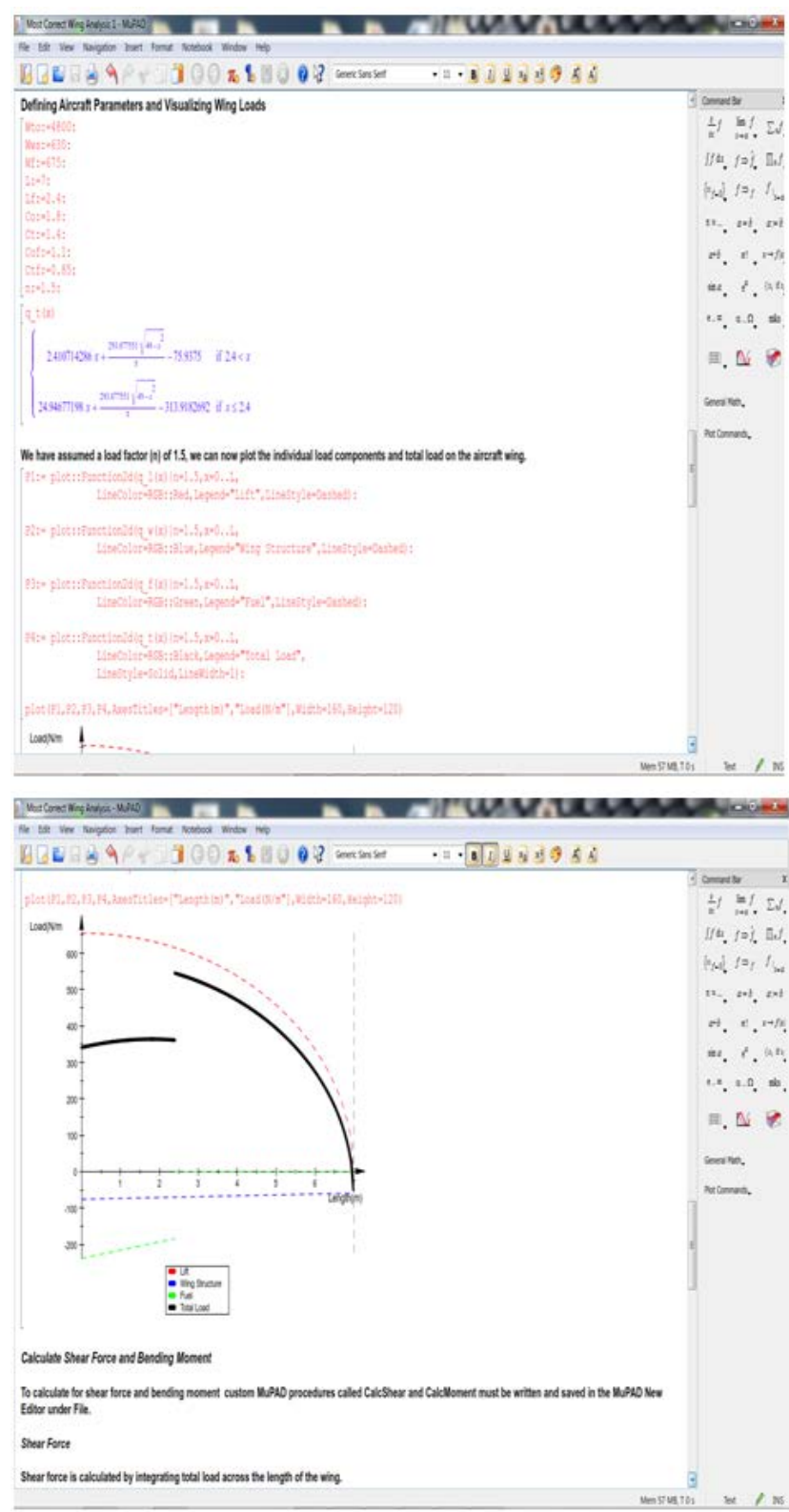

Figure 6. MATLAB generated plot for the various load components along the length of the aircraft wing

\subsubsection{Analysis and Discussion}

Figure 6 revealed that lift is the largest contributor to total load followed by fuel load which contributes significantly, while the weight of the wing is the least contributor. The maximum total load of $545.11 \mathrm{~N} / \mathrm{m}$ occurred at the end of the fuel tank $2.40 \mathrm{~m}$ along the wing's length. The disconnect between the lines of total load is from the piecewise equations $\left(L_{f}<x\right.$ and $\left.x \leq L_{f}\right)$ along the wing's length. 


\subsection{Results for Shear Force and Discussion}

The shear force distribution along the length of the wing is reflected in Figure 7 below:

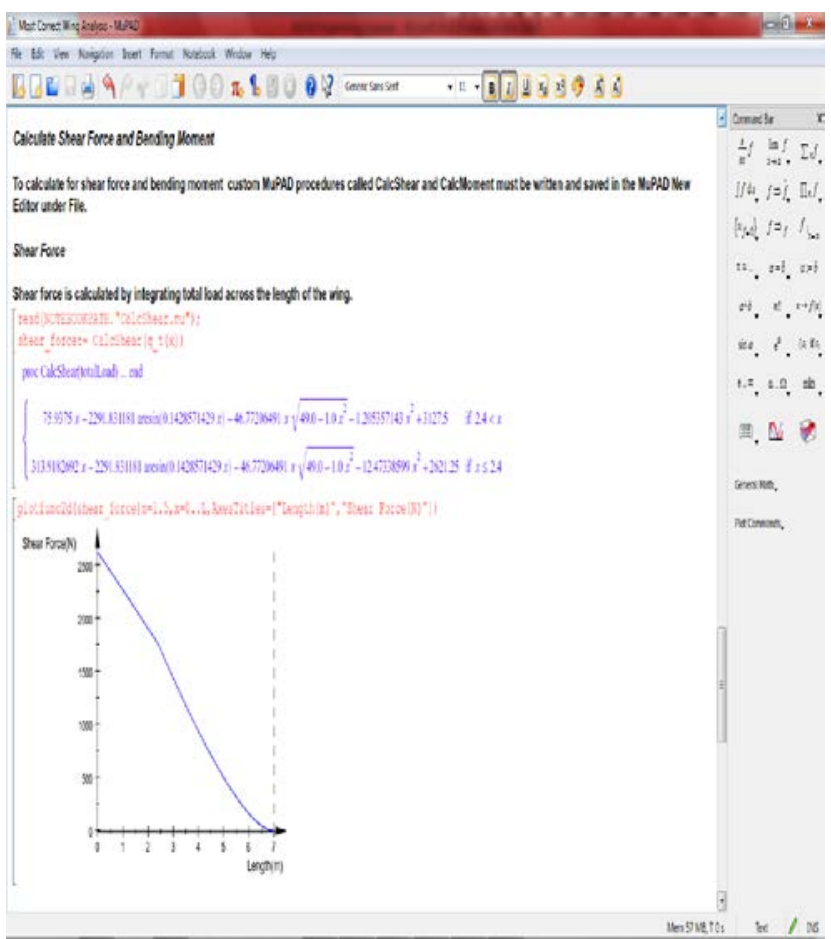

Figure 7. MATLAB generated plot for shear force

Figure 7 shows that the shear force generated is approximately $3,000 \mathrm{~N}$ which increases from the tip to the root of the wing.

\subsection{Results for Bending Moment Distribution}

The bending moment distribution along the length of the wing with the help of MATLAB is reflected in Figure 8 below:

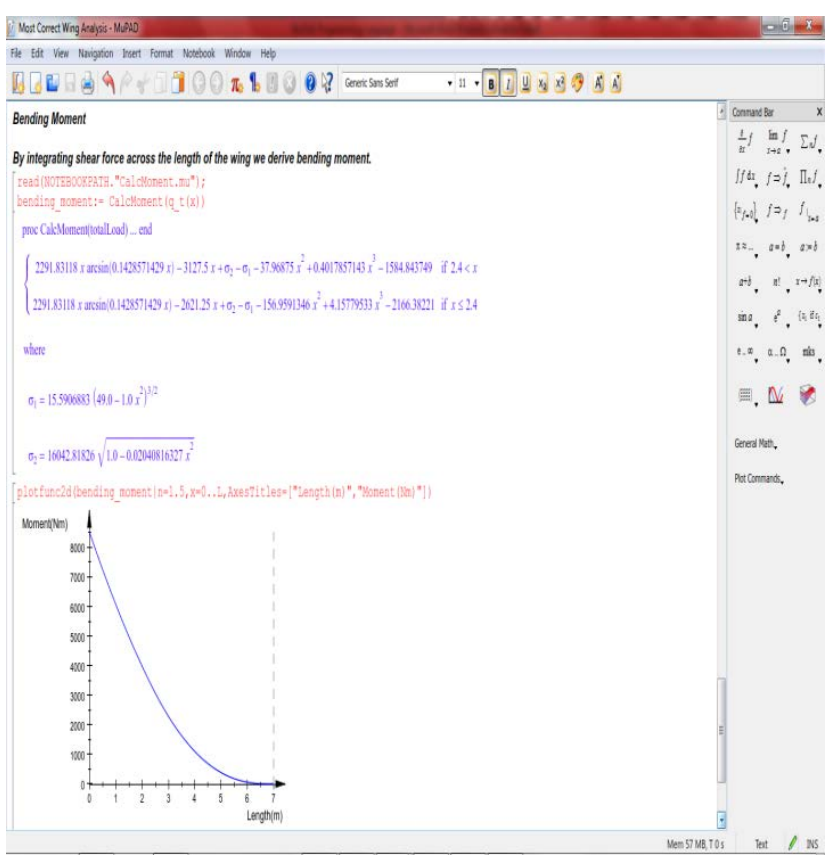

Figure 8. MATLAB generated plot for bending moment along the length of the aircraft wing.
As expected in Figure 8, since wings of an aircraft during take-off will bend upwards unlike most structural cantilever beams, bending moment is highest at the wing root with a value of $10,000 \mathrm{Nm}$ which approaches zero as it extends towards the tip of the wing of the aircraft.

\subsection{ANSYS Wing Spar Design Analysis.}

The analyses of the spar for the material considerations are reflected in Figure 9 through Figure 23.

\subsubsection{Graphical Results of Low Modulus Graphite_Epoxy Spar}

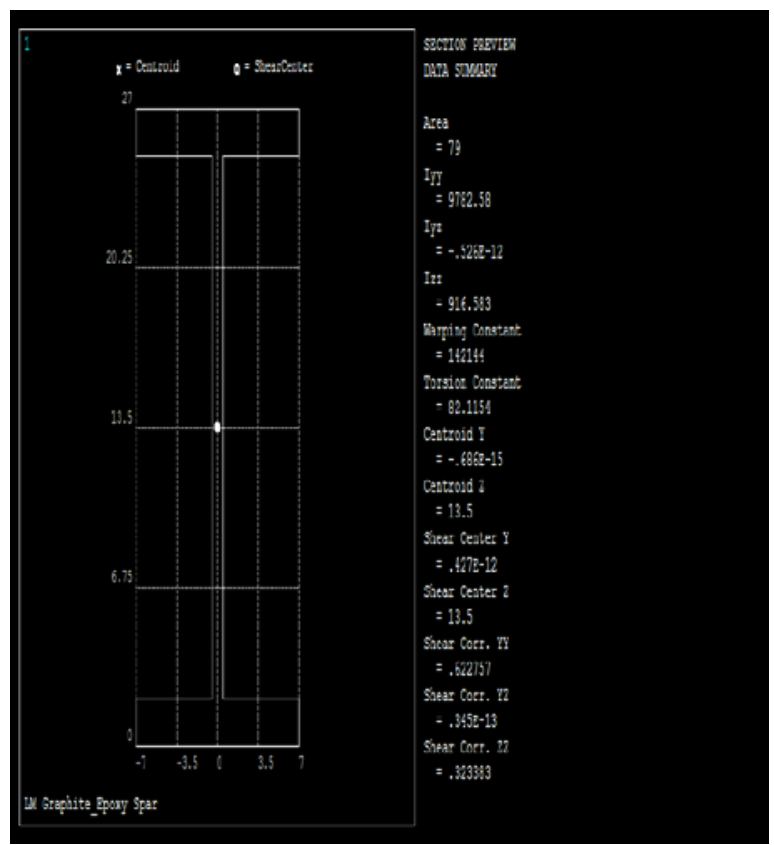

Figure 9. Section Preview of LM Graphite_Epoxy Spar

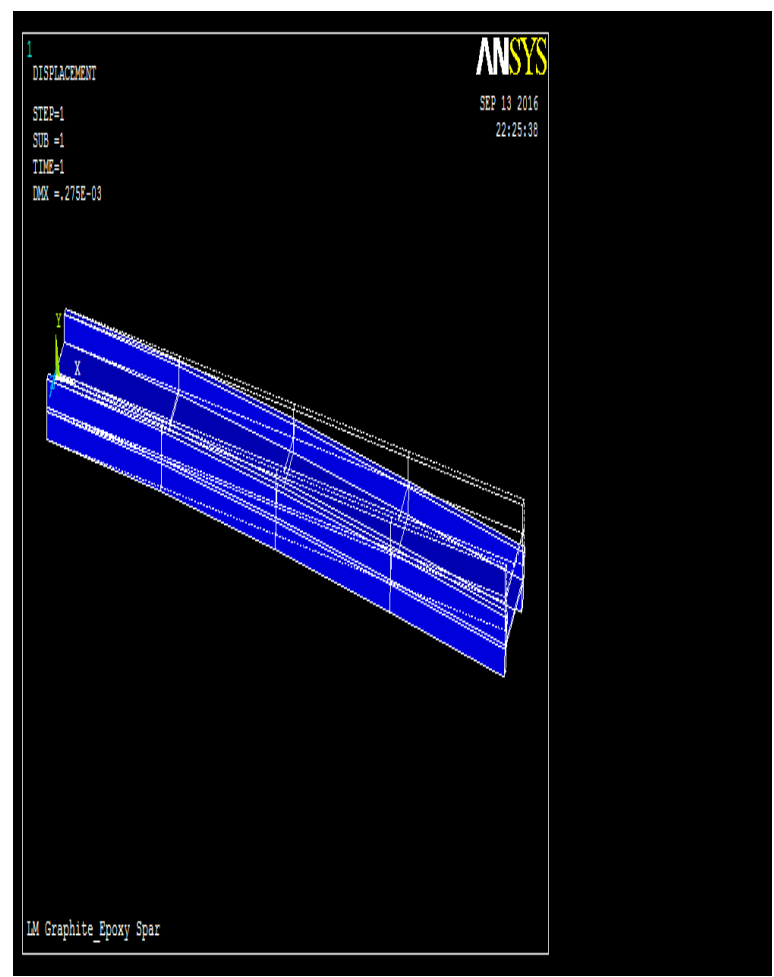

Figure 10. Deflection of LM Graphite_Epoxy Spar 


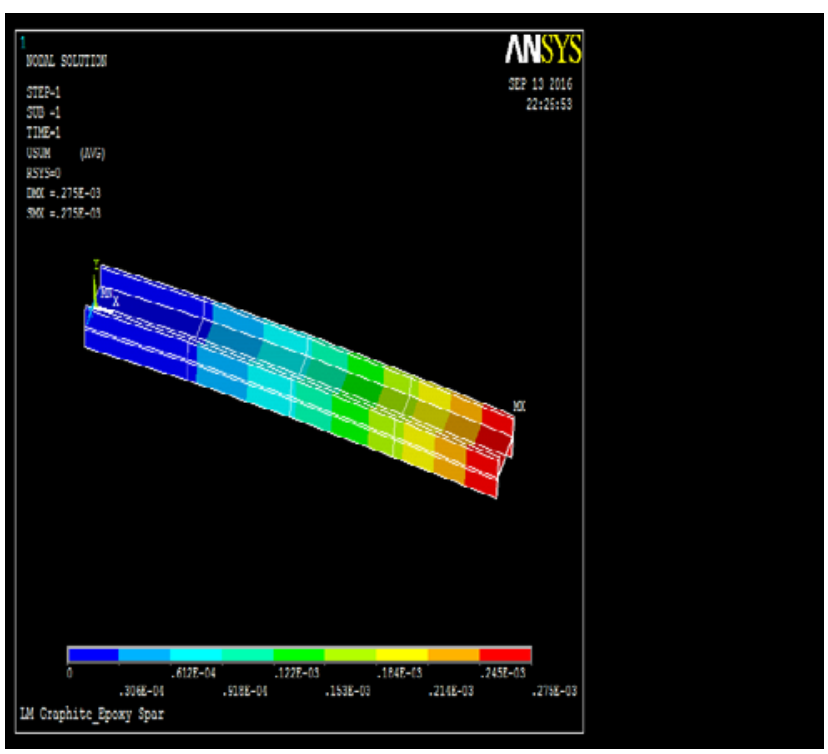

Figure 11. Nodal Solution of Deflected LM Graphite_Epoxy Spar

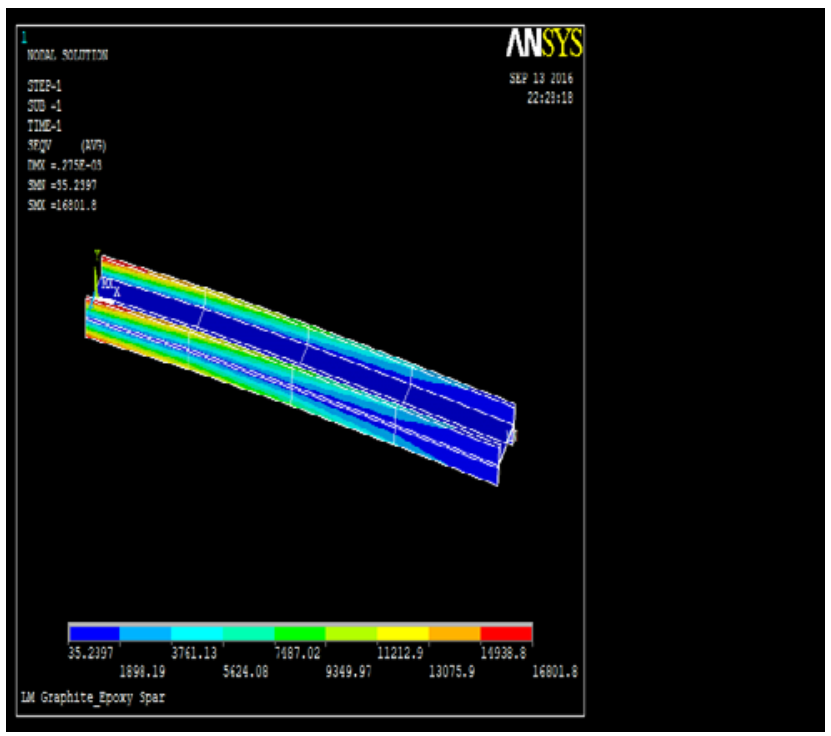

Figure 12. Von Mises Stress of LM Graphite_Epoxy Spar

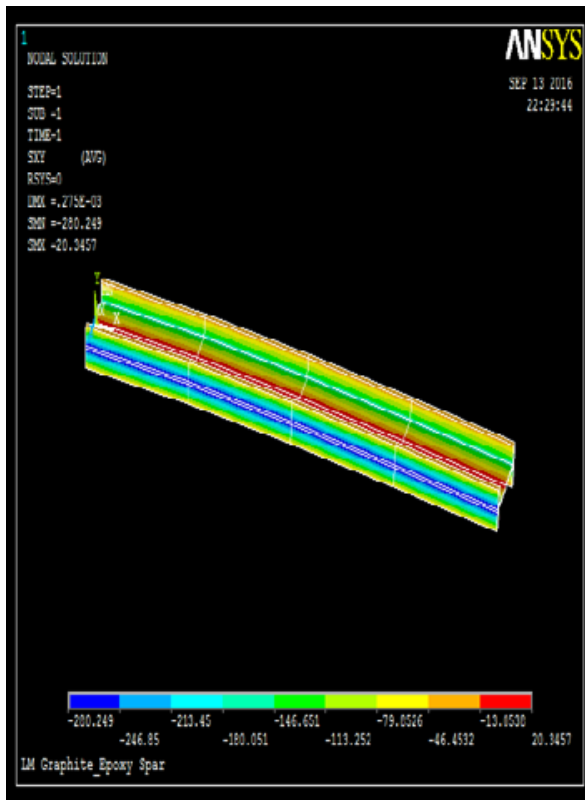

Figure 13. XY Shear Stress of LM Graphite_Epoxy Spar

\subsubsection{Graphical Results of High Modulus Graphite_Epoxy Spar}

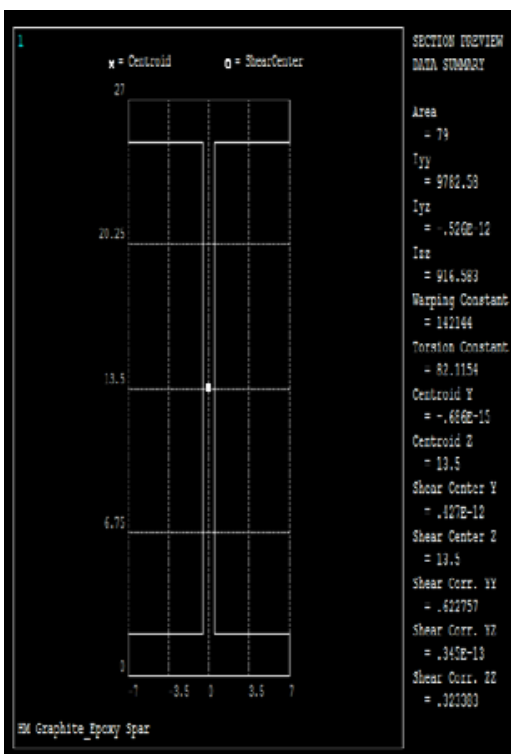

Figure 14. Section Preview of HM Graphite_Epoxy Spar

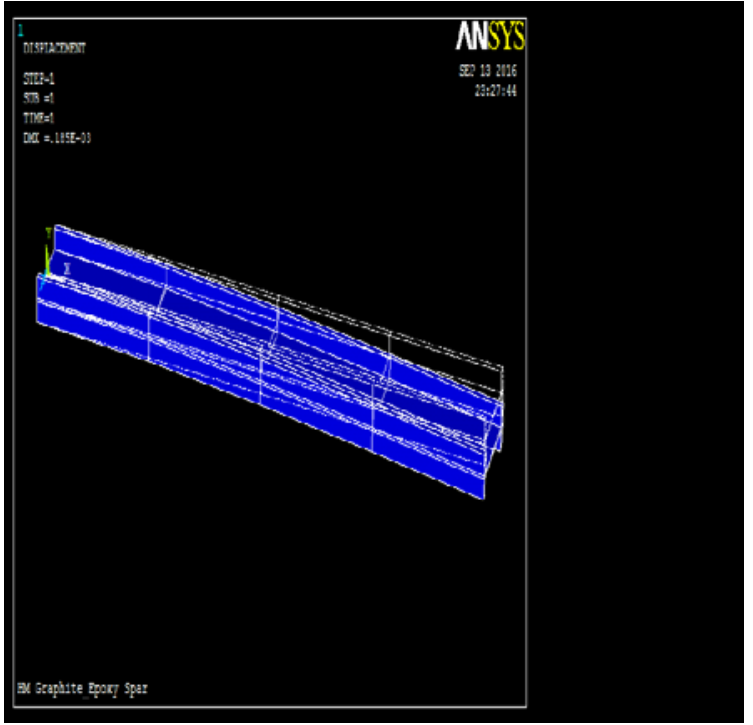

Figure 15. Deflection of HM Graphite_Epoxy Spar

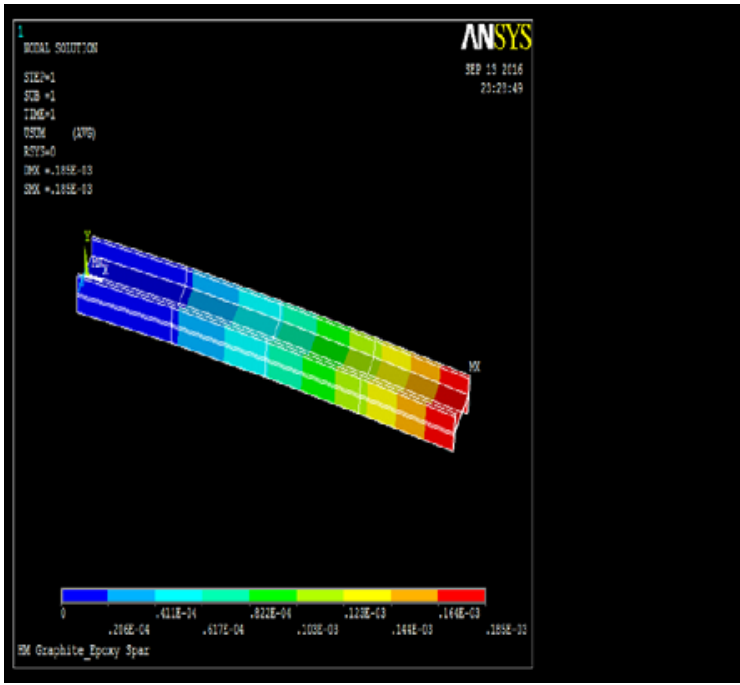

Figure 16. Nodal Solution of Deflected HM Graphite_Epoxy Spar 


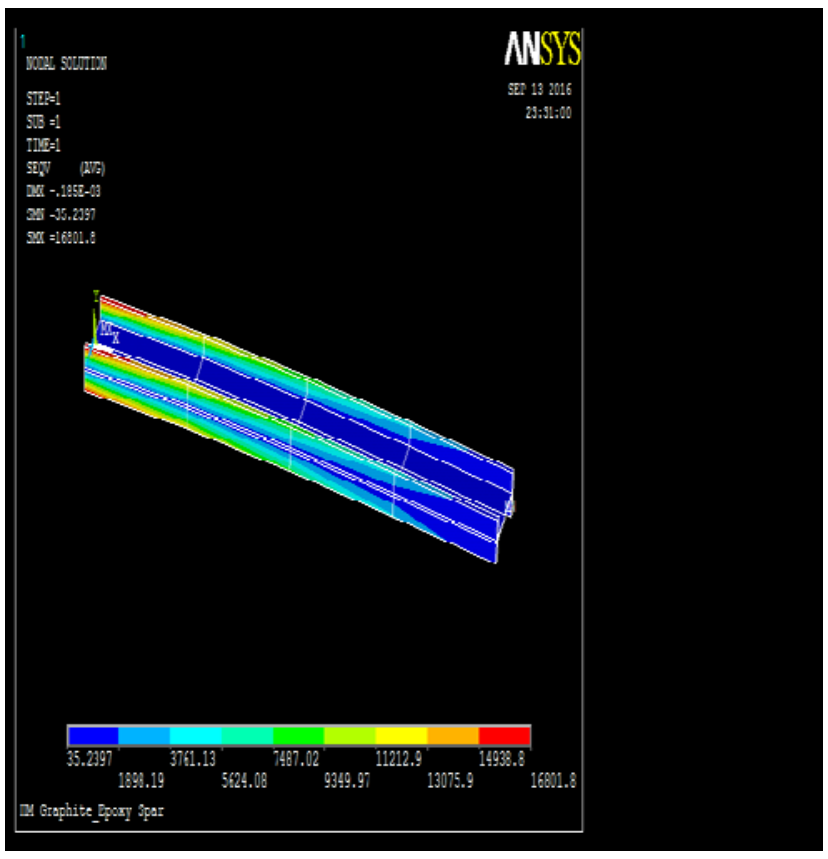

Figure 17. von Mises Stress of HM Graphite_Epoxy Spar

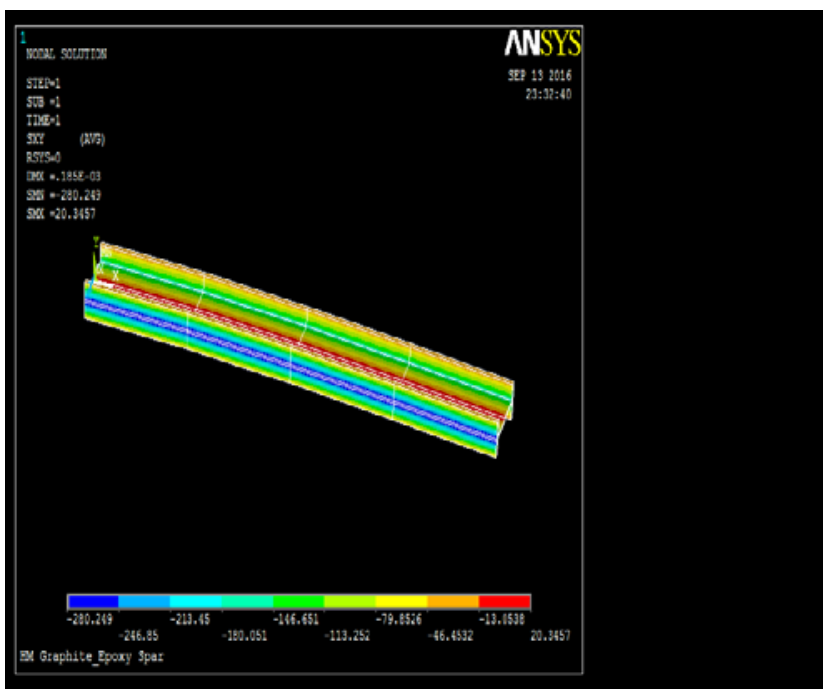

Figure 18. XY Shear Stress of HM Graphite_Epoxy Spar

\subsubsection{Graphical Results of Ultra Modulus}

Graphite_Epoxy Spar

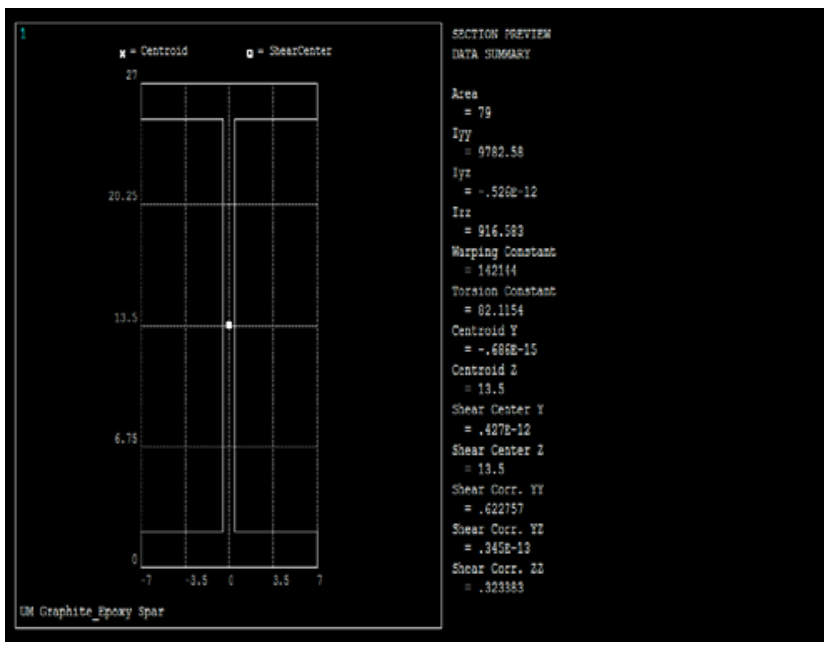

Figure 19. Section Preview of UM Graphite_Epoxy Spar

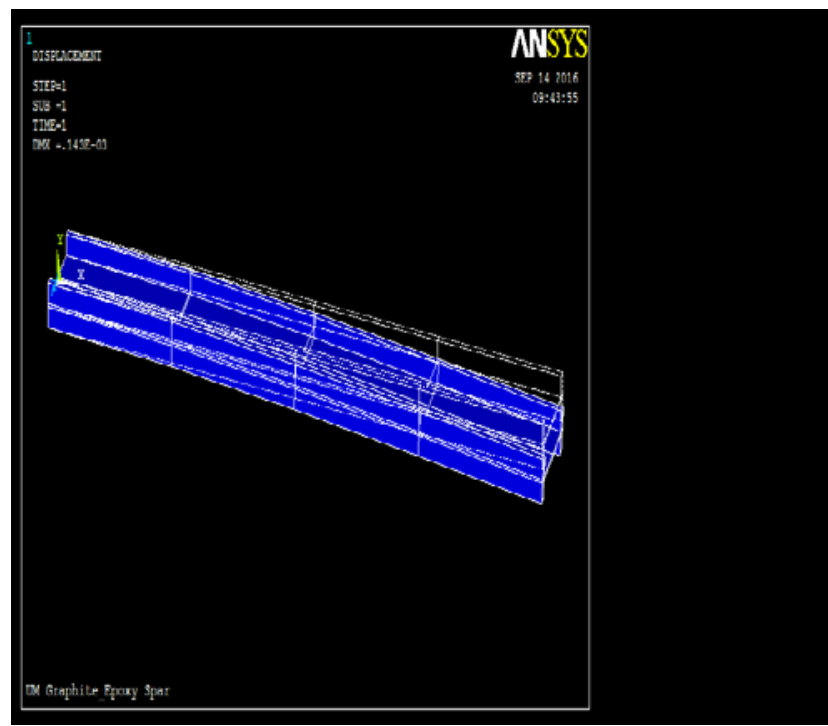

Figure 20. Deflection of UM Graphite_Epoxy Spar

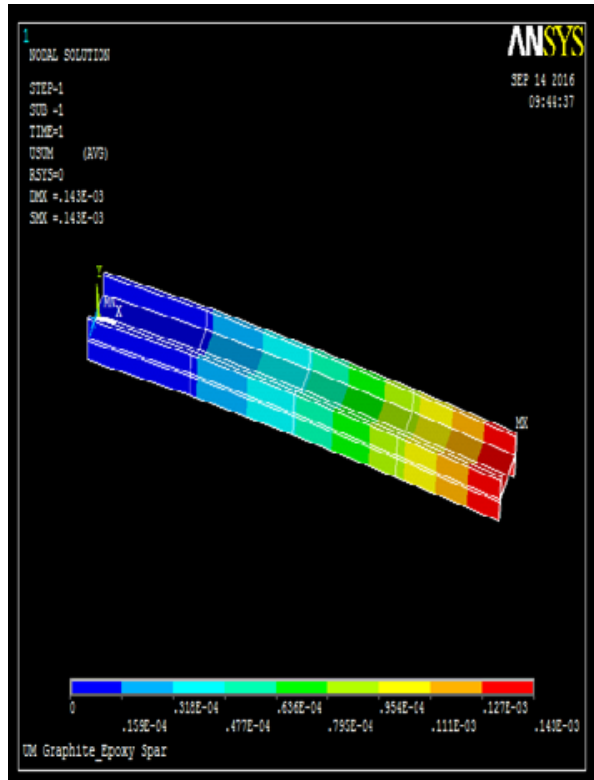

Figure 21. Nodal Solution of Deflected UM Graphite_Epoxy Spar

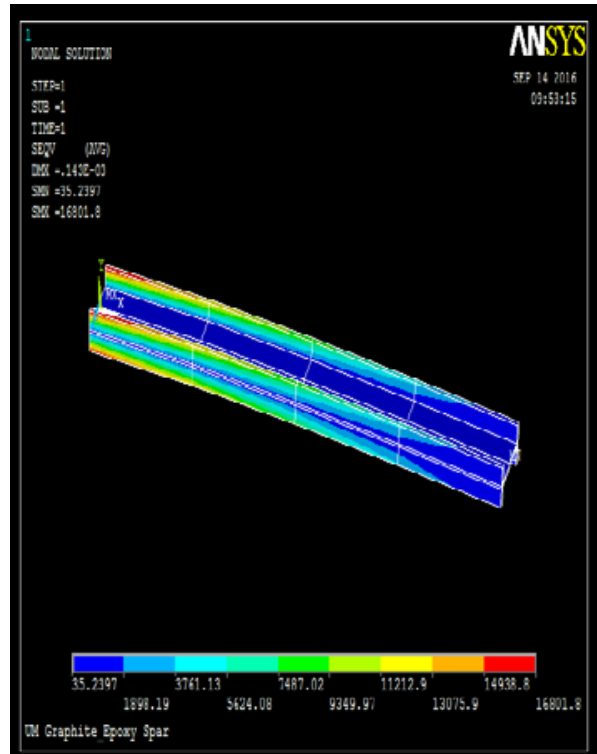

Figure 22. Von Mises Stress of UM Graphite_Epoxy Spar 


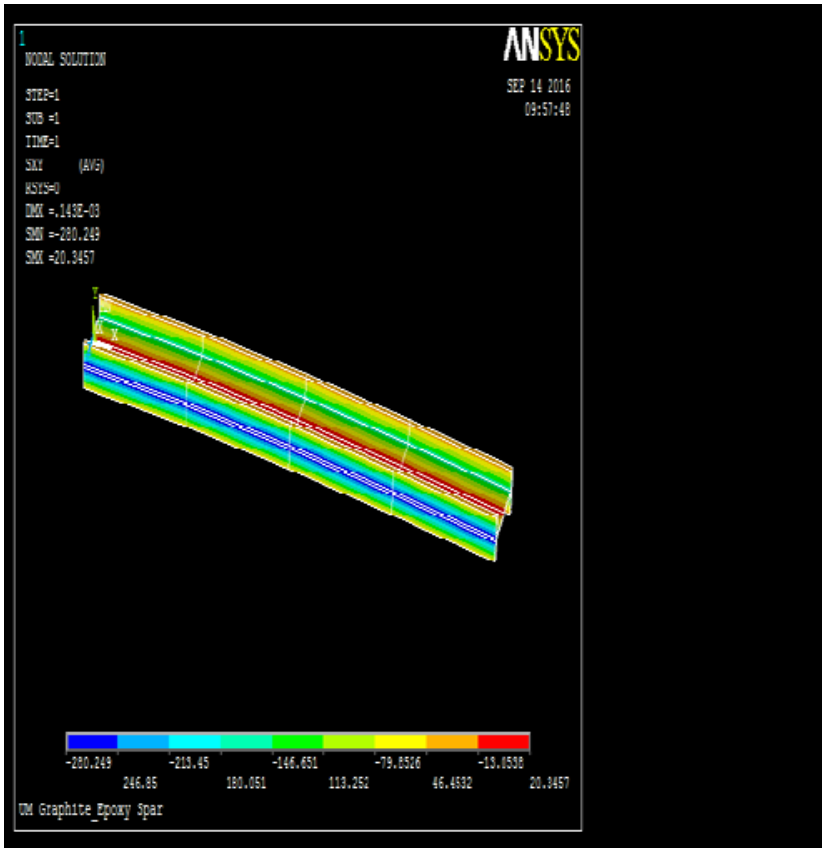

Figure 23. XY Shear Stress of UM Graphite_Epoxy Spar

\subsection{Tabulated Summary Results}

Table 5. Results of the Various Graphite_Epoxy Spar Designs

\begin{tabular}{|c|c|c|c|c|}
\hline S/N & Spar Designs & \multicolumn{3}{|c|}{ Analyses Results } \\
\hline & & $\begin{array}{c}\text { Deflection } \\
(\mathrm{m})\end{array}$ & $\begin{array}{c}\text { von Mises } \\
\text { Stress }\left(\mathrm{N} / \mathrm{m}^{2}\right)\end{array}$ & $\begin{array}{c}\text { XY Shear } \\
\text { Stress }\left(\mathrm{N} / \mathrm{m}^{2}\right)\end{array}$ \\
\hline A. & $\begin{array}{c}\text { LM } \\
\text { Graphite_Epoxy } \\
\text { Spar }\end{array}$ & $0.275 \mathrm{E}-03$ & $16,801.8$ & 20.3457 \\
\hline B. & $\begin{array}{c}\text { Graphite_Epoxy } \\
\text { Spar }\end{array}$ & $0.185 \mathrm{E}-03$ & $16,801.8$ & 20.3457 \\
\hline C. & $\begin{array}{c}\text { Graphite_Epoxy } \\
\text { Spar }\end{array}$ & $0.143 \mathrm{E}-03$ & $16,801.8$ & 20.3457 \\
\hline
\end{tabular}

From Table 5, the three spar designs show the same values of $16,801.8 \mathrm{~N} / \mathrm{m}^{2}$ for Von-Mises failure stress which is way beyond the applied bending stress of $10,000 \mathrm{Nm}$ generated by the wing loads. However, UM graphite-epoxy spar design shows the least deflection with $0.143 \times 10^{-3} \mathrm{~m}$ compared to the other designs. It can also be deduced from the table that the wing spars are poor handlers of shear stresses with as low as $20.35 \mathrm{~N} / \mathrm{m}^{2}$ out of the shear value of $3000 \mathrm{~N}$.

\section{Conclusion and Recommendations}

\subsection{Conclusion}

This research work has identified the various loads acting on the wings of an aircraft; aerodynamic lift, load due to wing structure weight and load due to the weight of fuel contained in the wing. Analytical models were derived in Symbolic Math Toolbox notebook interface called MuPAD in MATLAB software. Shear force and bending moments resulting from these loads for a small passenger aircraft are approximately 3,000N and 10,000Nm respectively. The wing spars have been designed to withstand these developed forces.

The ANSYS 14 Mechanical APDL software provided a very close approximation to actual manufacturing process defined within simulation environments. Wing spar design was carried out by defining elements, materials, crosssection and geometry of the spar. The solid model was then created with the loads and boundary conditions specified. Standard results such as deformations and stresses were therefore displayed on graphical windows.

ANSYS 14 Mechanical APDL which is FEA software provided accurate analysis and results since solid models of the spar could be meshed via finite element method.

Results from the analysis for spar designs revealed that, the three designs of LM, HM and UM failed at 16,801.8 $\mathrm{N} / \mathrm{m}^{2}$ which is above the wing bending moment of $10,000 \mathrm{Nm}$ with UM spar having the least deflection of $0.143 \times 10^{-3} \mathrm{~m}$ because of its high stiffness property. However, all the spar designs demonstrated very poor ability to withstand the shear force acting on the wing of the aircraft.

\subsection{Recommendation}

Further research recommendation will be to investigate using computational technique the mechanical behaviour of graphite-epoxy laminate wing skin designs for various stacking sequences capable of withstanding the developed shear forces across the wing span.

\section{References}

[1] ANSYS, Inc., (2013); "ANSYS Mechanical APDL Structural Analysis Guide," vol. Release 15, pp. 435-447.

[2] Carl Zweben. Wiley Online Library (COMPOSITE MATERIALS). [Online].

http://onlinelibrary.wiley.com/doi/10.1002/9781118985960.meh1 10/pdf. Retrieved September 20, 2016.

[3] Dan Doherty, "Toolbox, Analytical Modeling of Aircraft Wing Loads Using MATLAB and Symbolic Math”. [Online].

https://www.mathworks.com/company/newsletters/articles/analyti cal-modeling-of-aircraft-wing-loads-using-matlab-and-symbolicmath-toolbox.html. Retrieved May 18, 2016.

[4] Dynamic Flight, Inc., "Airfoil in General”. [Online]. http://www.dynamicflight.com/aerodynamics/airfoils/. Retrieved on September 30, 2016.

[5] Ithurbure R.P., (1999); "Design of the Wing of a Regional Airliner in Composite Materials," Delft University of Aerospace Engineering, Delft, Memorandum-864.

[6] Jeff Scott, "Aerospaceweb.org”. [Online]. http://www.aerospaceweb.org/question/airfoils/q0041.shtml. Retrieved September 30, 2016.

[7] Khurmi R.S. and Gupta J.K., (2008); “A Textbook of Machine Design”, 4th ed., New Delhi, India: S. Chand \& Company Ltd.

[8] Mohamed H. A. and Nithiyakalyani S., (2014); "Design and Structural Analysis of the Ribs and Spars of Swept," International Journal of Emerging Technology and Advanced Engineering, vol. 4, no. 12, pp. 208-213.

[9] Myer K., (2002); "Handbook of Materials Selection”. New York, United States of America: John Wiley and Son.

[10] National Academy of Engineering, "Link Engineering Web site". [Online]. http://www.greatachievements.org/?id=3817. Retrieved on November 6, 2015.

[11] Roy Beardmore, "Roymechx". [Online]. http://www.roymech.co.uk/Useful_Tables/Beams/Beam_theory.ht ml. Retrieved September 30, 2016. 
[12] Tim P. and Bernadette B.V., (2015); The Dibner Institute for History of Science and Technology Web site. [Online].

http://authors.library.caltech.edu/5456/1/hrst.mit.edu/hrs/materials /public/composites/Composites_Overview.htm. Retrieved on November 6, 2015.

[13] Victor D. and Bikramjit D., (2014); "Deflection and Stress Analysis of a Beam on Different Elements Using ANSYS APDL,"
International Journal of Mechanical Engineering and Technology (IJMET), vol. 5, no. 6, pp. 70-79.

[14] World Intellectual Property Organization (WIPO), "A Patent that Changed an Industry". [Online].

http://www.wipo.int/ipadvantage/en/details.jsp?id=2909.

Retrieved on September 15, 2015. 